\title{
Fucoxanthin protects neonatal rat cardiomyocytes and attenuates high glucose-mediated oxidative stress via the AMPK pathway
}

\author{
Fengyue $\mathrm{Li}^{1}$, Chunxia Lei ${ }^{2}$
}

\begin{abstract}
${ }^{1}$ Department of Pediatrics, Jiangsu Taizhou People's Hospital, Taizhou City, Jiangsu Province, China

${ }^{2}$ Department of Neonatology, Wuhan Children's Hospital (Wuhan Maternal and Child Healthcare Hospital), Tongji Medical College, Huazhong University of Science and Technology, Wuhan, Hubei, China
\end{abstract}

Submitted: 10 October 2019

Accepted: 15 February 2020

Arch Med Sci

DOI: https://doi.org/10.5114/aoms.2020.94432

Copyright $\odot 2020$ Termedia \& Banach

\section{Abstract}

Introduction: Diabetic cardiomyopathy (DC) is associated with impaired diastolic function. Hyperglycemia-mediated oxidative stress and apoptosis are the major factors responsible for DC. Also NADPH oxidase is the main source of ROS in cardiac cells or cardiomyocytes. Here we evaluated the effect of fucoxanthin (FXN) on high glucose cultured neonatal rat cardiomyocytes.

Material and methods: For the study, Iry neonatal rat cardiomyocytes were cultured in a high glucose environment $(30 \mathrm{mM} / \mathrm{l})$ in the presence and $a b$ sence of FXN. Apoptosis, cell viability, activity of NADPH oxidase and expression level of its subunits, levels of MDA and activity of endogenous antioxidant enzymes were studied. We also confirmed the involved pathway by studying the expression of AMPK, GSK-3 $\beta$ and Akt in the cardiomyocytes.

Results: The high glucose environment increased the production of ROS, and FXN decreased the oxidative burden by inhibiting ROS in cultured neonatal rat cardiomyocytes. FXN inhibited the activity of NADPH oxidase and Rac1 also increased the expression of its subunits. Treatment of FXN reversed the MDA, CAT, GSHpx, SOD activity and GSH contents. FXN down-regulated the levels of $\mathrm{Bax}$ and up-regulated the levels of $\mathrm{BCl}-2$ (anti-apoptotic protein); treatment protected the cardiomyocytes from injury. Also, FXN increased the levels of pAMPK in cardiac cells treated with high glucose. The pharmacological inhibitor of AMPK abolished the activities of FXN in high glucose induced cardiomyocytes.

Conclusions: FXN exerted protective action on cardiac cells subjected to high glucose-mediated apoptosis by suppressing NADPH oxidase-mediated production of ROS and maintaining the antioxidant defense in the tissues. The attenuating activity of FXN was propagated via the AMPK cascade.

Key words: diabetic cardiomyopathy, fucoxanthin, NADPH oxidase, oxidative stress.

\section{Introduction}

Cardiovascular diseases (CVD) are a group of diseases such as ischemia, coronary heart diseases and hypertension which involve the heart and blood vessels. CVD is one of the main causes of deaths in diabetic patients. Studies reveal that microvascular and macrovascular injuries

\author{
Corresponding author: \\ Dr. Chunxia Lei \\ Department of Neonatology \\ Wuhan Children's Hospital \\ Wuhan Maternal and \\ Child Healthcare Hospital \\ Tongji Medical College \\ Huazhong University \\ of Science and Technology \\ 100 of Xianggang Road \\ Wuhan, Hubei 430000, China \\ Phone/fax: \\ +862782433163 \\ E-mail: ClarkPetersonmza@ \\ yahoo.com
}


are the major contributing factors for increased incidence of CVD [1]. In addition to these vascular injuries, both clinical and preclinical evidence demonstrates the presence of diabetes-mediated cardiomyopathy, which generally shows changes in cardiac cells, i.e. cardiomyocytes. 'Diabetic cardiomyopathy' (DC) is characterized by impaired diastolic function along with progression of cardiomyocyte apoptosis, hypertrophy and myocardial fibrosis [2].

The mechanisms involved in diabetes-mediated cardiac damage are complex and multi-factorial. The increased burden of reactive oxygen species due to the hyperglycemic condition is the prime contributor to diabetes-mediated cardiac complications [3]. Cardiac tissues of diabetic patients are more prone to oxidative damage compared to those of non-diabetics; under normal physiological conditions the burden of reactive oxygen species is eliminated by the antioxidant defense of the body. It has been evidenced that both hyperglycemic and diabetic conditions contribute to impairing the endogenous antioxidant system [4]. Once the burden of reactive oxygen species exceeds the capability of the body's antioxidant system, the excessive reactive species start damaging the integrity of DNA, alter protein function, damage membrane lipids, and cause necrosis and apoptosis [5]. $\mathrm{NADPH}$ oxidase has been identified as one of the key sources for generating myocardial reactive oxygen species under diabetic conditions [6]. It is responsible for reducing NADPH to oxygen, which leads to generation of superoxide anion. The continuous activation of NADPH oxidase may further lead to decrease of intracellular NADPH, causing impairment of the antioxidant system [7]. Confirming the important character of oxidative stress in the development of diabetes-mediated cardiac complications, there is rising importance of the therapies involving antioxidants.

Fucoxanthin (FXN) is one of the most abundant carotenoids obtained from seaweeds [8]. Due to the presence of special functional groups which include a 5,6-monoepoxide structure and an allenic bond, FXN shows a variety of pharmacological activities such as antioxidant activity by curbing oxidative stress and an anti-inflammatory effect [9]. FXN has also been reported to show anticancer, anti-angiogenic, anti-apoptotic, antiproliferative [10], anti-obesity and very importantly anti-diabetic activity [11]. Though previous studies have shown that FXN is an anti-diabetic agent, none of the reports have investigated the potential role of FXN in the pathogenesis of diabetic cardiomyopathy.

In the present study, we evaluated the role of FXN in diabetic cardiomyopathy by treating primary neonatal rat cardiomyocytes pre-exposed to a high glucose environment. We also studied the potential pathways involved.

\section{Material and methods}

\section{Reagents and antibodies}

Fucoxanthin (FXN) was procured from SigmaAldrich (USA). Fetal bovine serum (FBS) was bought from Sigma-Aldrich (USA). Dulbecco's modified eagle's medium (DMEM) and collagenase type-2 were obtained from Thermo Fisher (USA). Cell Counting Kit 8 (WST-8/CCK8) (ab228554) was procured from Abcam (USA). Dorsomorphin dihydrochloride (DDH), an AMPK inhibitor, was procured from Santacruz Biotech (USA). For determining oxidative stress markers, Lactate dehydrogenase (LDH) and Malondialdehyde (MDA) kits from Abcam (USA), Catalase (CAT) and Glutathione (GSH) assay kits were obtained from Sigma-Aldrich (USA). Superoxide Dismutase (SOD) and ROS kits were supplied by Thermo Fisher (USA). The PI and Annexin V-FITC kit was procured from BestBio, China. For TUNEL assay the kit was obtained from Roche, Germany. The Rac1 Activation Assay Kit and NADPH activity assay kit were obtained from Abcam (USA). The antibodies used for the study were $\mathrm{p} 22^{\text {phox }}, \mathrm{p}$-Akt, Akt, p-AMPK $\alpha, \mathrm{p} 67^{\text {phox }}, \mathrm{Bcl}-2$, p-GSK-3 $\beta$, Bax, $\beta$-actin and GSK-3 $\beta$, obtained from Cell Signaling Tech. (USA), whereas $p 47^{\text {phox }}$ and gp$91^{\text {phox }}$ were supplied by Santa Cruz Biotech, (USA).

\section{Animal studies}

For the present study Sprague-Dawley neonatal rats aged 1 to 3 days were chosen. The animals were provided by the central animal house of Wuhan Children's Hospital. All the animal studies adhered strictly to the draft Animal protection law of the People's Republic of China (2009) for experimental animals. The animal experiments received approval from the animal ethical committee of Wuhan Children's Hospital, China; the approval number was WCH0784-A

\section{Isolation of cardiomyocytes from neonatal rats, culture and treatment}

The cardiomyocytes were isolated from the neonatal rats as per the procedure described previously [12]. The isolated cardiomyocytes were cultured in controlled atmospheric conditions of $5 \% \mathrm{CO}_{2}$ at $37^{\circ} \mathrm{C}$ in DMEM supplemented with FBS $(10 \%)$, streptomycin $(100 \mathrm{mg} / \mathrm{ml})$ and penicillin $(100 \mathrm{U} / \mathrm{ml})$. About $1 \times 10^{6}$ cells were used for every experiment. The cardiomyocytes were then exposed to a variety of glucose containing medium ranging from 5 to $50 \mathrm{mM} / \mathrm{l}$ of D-glucose for $72 \mathrm{~h}$. The treatment of $30 \mathrm{mM}$ was selected as high glucose concentration; mannitol (30 mM/l) 
was selected as an osmotic control. The high glucose concentration treated cells were treated with FXN (40 $\mu \mathrm{M}$ unless noted otherwise) for $24 \mathrm{~h}$. DDH $(10 \mu \mathrm{M})$ was added to the media $1 \mathrm{~h}$ before the cells were treated with glucose or FXN.

\section{Cell viability studies}

A cell counting kit-8 (Abcam USA) was used to measure cell viability of cardiomyocytes following the supplier's protocol. Briefly, for cell viability assay the conversion of water soluble tetrazolium salt to water soluble formazan dye takes place due to reduction by dehydrogenases [13]. The cardiomyocytes were grown in 96-well plates for $48 \mathrm{~h}$ and were supplemented with various concentrations of FXN $(5,10,20,40,80 \mu \mathrm{M})$, then the plates were incubated for $12 \mathrm{~h}$ in an incubator. The cells were washed and $10 \mu$ of CCK- 8 reagent was transferred to each well and incubated at $37^{\circ} \mathrm{C}$ for $2 \mathrm{~h}$. A microplate reader (Lambda, Bio-20) was used to record the optical activity at $450 \mathrm{~nm}$. Percent cell viability was calculated relative to the control (untreated cells).

\section{Biochemical evaluation}

Activity of LDH was evaluated according to its property to catalyze the reaction between lactic and pyruvic acid. The levels of markers of oxidative stress were analyzed by measuring malondialdehyde (MDA) by the TBARS method. The activity of the antioxidant enzyme SOD was done by measuring its capacity to inhibit the oxidation of oxymine. The CAT activity was assessed by measuring the decomposition of hydrogen peroxide per minute. The activity of GSHpx was assessed by measuring the decomposition rate of hydrogen peroxide and oxidation of glutathione. The assay for measuring markers of oxidative stress was done by a colorimetric method using a microplate reader. The protein was estimated by a protein estimation kit (Sigma-Aldrich USA).

\section{Measurement of intracellular ROS}

The measurement of intracellular superoxide anions was based on high performance liquid chromatographic assay and dihydroethidium fluorescence probe. The target cells (cardiomyocytes) were rinsed at least 3 times using cold Dulbecco's phosphate-buffered saline and were then incubated with dihydroethidium $(10 \mu \mathrm{M})$ for $20 \mathrm{~min}$ at room temperature. The cells were washed after incubation, to remove free dihydroethidium, the cells were viewed using a fluorescence microscope (Olympus, Japan) and images were recorded. HPLC (Waters Alliance, USA) assay was carried out for analyzing the generation of intracellular generated ROS using a dihydroethidium probe at excitation wavelength of $490 \mathrm{~nm}$ and emission wavelength of $596 \mathrm{~nm}$ [14]. The procedure was followed by incubation of cardiomyocytes in DMEM medium supplemented with dihydroethidium $(10 \mu \mathrm{M})$ for $30 \mathrm{~min}$; the cells were then harvested and were permeabilized with $0.1 \%$ Triton X100 in Dulbecco's phosphate-buffered saline, and protein estimation was done using protein estimation kit Sigma-Aldrich (USA). About $100 \mu \mathrm{l}$ of cell lysate was transferred to a mixture containing $0.2 \mathrm{~mol} / \mathrm{l}$ of $\mathrm{HClO}_{4}$ and methanol (50:50\%v/v); the resultant was incubated in an ice bath for $3 \mathrm{~h}$ for protein precipitation. The mixture was subjected to cooling centrifugation at $4^{\circ} \mathrm{C}$ and $12000 \mathrm{~g}$ for $30 \mathrm{~min}$; about $100 \mu \mathrm{l}$ of supernatant was mixed with $100 \mu \mathrm{l}$ of phosphate buffer saline ( $\mathrm{pH}$ 2.6). The resultant mixture was centrifuged again before subjecting it to HPLC analysis.

\section{TUNEL assay for detection of apoptotic cells}

TUNEL assay, i.e. terminal deoxynucleotidyl transferase-mediated dUTP nick end-labeling, was carried out for detection of apoptosis in cardiomyocytes. An in Situ Cell Death Detection Kit, Fluorescein (Sigma-Aldrich USA) was used for the study following the supplied instructions. Briefly, the cells were rinsed three times using Dulbecco's phosphate-buffered saline after the defined treatments and then fixed with paraformaldehyde $(4 \%)$ at $37^{\circ} \mathrm{C}$ in the dark. The cells were incubated with protein kinase for $20 \mathrm{~min}$ at $37^{\circ} \mathrm{C}$, after which the cells were treated with $\mathrm{H}_{2} \mathrm{O}_{2}(3 \%)$ for $20 \mathrm{~min}$ at $37^{\circ} \mathrm{C}$. The cells were rinsed three times with phosphate buffer saline and were treated with the TUNEL detection kit. The cells were stained using 3,3'-diaminobenzidine followed by staining with hematoxylin. The images were taken using fluorescence microscopy (Olympus, Japan).

\section{Annexin V-FITC and propidium iodide (PI) staining for detection of apoptosis}

The apoptosis of cardiomyocytes was also detected by a dual staining approach using an Annexin V-FITC and PI kit with the help of a flow cytometer (Life Science Research, Bio-Rad USA). About $1 \times 10^{6}$ cells/well were transferred to a 96well plate and exposed to FXN $(40 \mu \mathrm{M})$. The cells were centrifuged and were resuspended in binding buffer to produce a volume of $100 \mu$, to which $5 \mu \mathrm{l}$ of staining solution (Annexin V-FITC and PI) was added, the cells being given a gentle swirl to mix. The cells were then incubated for $20 \mathrm{~min}$ in the dark at $37^{\circ} \mathrm{C}$. The cells were collected and to each well binding buffer $(400 \mu \mathrm{l})$ was added followed by flow-cytometer study immediately. 


\section{Evaluation of Rac1 activity}

The Rac1 activity was determined by precipitation of Rac1-GTP from cell lysates; the activity was measured by a Rac1 specific monoclonal antibody. A Rac1 activation kit (Abcam, USA) was used for the study. The cardiomyocytes were rinsed three times with Dulbecco's phosphate-buffer saline. The proteins from the cells were extracted using a cocktail of protease inhibitor. The homogenates were centrifuged at $10000 \mathrm{rpm}$ for $20 \mathrm{~min}$; the supernatant was used for measuring the activity for Rac1 pulldown assay followed by total Rac1 count. About $15 \mu \mathrm{l}$ of PAK1-PBD agarose beads were transferred to each well followed by incubation for $12 \mathrm{~h}$ at $4^{\circ} \mathrm{C}$. The GTP-bound Rac1 was obtained by centrifugation. Western blot analysis was done for studying the expression of total and active Rac1.

\section{Evaluation of NADP+/NADPH ratio}

The ratio of $\mathrm{NADP}^{+} / \mathrm{NADPH}$ was evaluated with the NADP/NADPH Kit (ab65349) in accordance with the supplied instructions. The evaluation was based on a cycling reaction of glucose dehydrogenase in which the developed NADPH causes reduction of the probe into an intense fluorescent product. The intensity of the formed product was measured at excitation wavelength of $530 \mathrm{~nm}$ and emission wavelength of $585 \mathrm{~nm}$, which was directly correlated to $\mathrm{NADP}^{+} / \mathrm{NADPH}$ present in the target sample.

\section{Immunohistochemistry and evaluation of Bcl-2 and Bax}

For immunohistochemical analysis, the cardiomyocytes were washed three times with Dulbecco's phosphate-buffered saline. All the three treatment groups of cells were fixed using paraformaldehyde $(4 \%)$ at $37^{\circ} \mathrm{C}$ for $20 \mathrm{~min}$ followed by permeabilization using TritonX-100 (0.1\%) for $10 \mathrm{~min}$. The resultant cardiomyocytes were inactivated by endogenous peroxidase along with $\mathrm{H}_{2} \mathrm{O}_{2}$ (3\%) for $15 \mathrm{~min}$ in the dark; the cells were blocked using BSA (5\%) for $20 \mathrm{~min}$ at $37^{\circ} \mathrm{C}$. The obtained cardiomyocytes were washed three times, after which the cells were incubated at $4^{\circ} \mathrm{C}$ for $12 \mathrm{~h}$ with anti Bcl-2 antibody at dilution 1:300 (Abcam, USA) and anti-Bax at dilution $1: 200$ (Abcam USA). The cells were supplemented with horseradish peroxidase conjugated IIry goat anti-rabbit IgG antibody and were incubated for $25 \mathrm{~min}$. The cells were visualized using $D A B$ and counterstained with hematoxylin dye; the slides were dehydrated with alcohol followed by a cover slip. The images were processed using Image-Pro software.

\section{Western blot study}

The cells were transferred to a 96-well plate followed by lysis using RIPA lysis buffer in an ice bath for $20 \mathrm{~min}$. The obtained lysates were subjected to centrifugation at $10000 \mathrm{rpm}$ for $20 \mathrm{~min}$ at $4^{\circ} \mathrm{C}$. The proteins in the cell lysates were estimated using a protein estimation kit (Sigma-Aldrich USA). The lysates were treated with antibodies such as Bax, GSK-3 $\beta, \mathrm{Bcl}-2, \mathrm{p}-\mathrm{AMPK} \alpha, \mathrm{p} 67^{\text {phox }}, \mathrm{AMPK} \alpha, \mathrm{p} 22^{\text {phox }}$, p67 $7^{\text {phox }}$, gp9 $1^{\text {phox }}$ p4 $7^{\text {phox }}$, pAkt, Akt, pGSK, GSK-3 $\beta$ (Cell Signaling, USA) and actin (Abcam, USA). The membranes were incubated along with horseradish peroxidase-conjugated $\mathrm{II}^{\text {ry }}$ antibody for $60 \mathrm{~min}$ at $37^{\circ} \mathrm{C}$. The obtained blots were developed using an ECL kit.

\section{Ethics approval}

The animals were provided by the central animal house of Wuhan Children's Hospital. All the animal studies strictly adhered to the draft Animal protection law of the People's Republic of China (2009) for experimental animals. The animal experiments received approval from the animal ethical committee of Wuhan Children's Hospital, China.

\section{Statistical analysis}

The statistical analysis was done using GraphPad Prism software. All the data presented in the manuscript are shown as mean \pm \%RD. The statistics was done using one-way analysis of variance (ANOVA) and Student-Newman-Keuls analysis. The values of $p<0.05$ were regarded as significant.

\section{Results}

Fucoxanthin enhanced the cell viability of neonatal cardiomyocytes treated with high glucose

To evaluate the function of FXN in cell survival, we studied cell viability of I $^{\text {ry }}$ cardiomyocytes obtained from neonatal rats treated with various concentrations of glucose ranging from 5 to $50 \mathrm{mM} / \mathrm{l}$ of D-glucose for $72 \mathrm{~h}$ (Figure $1 \mathrm{~A}$ ). The results suggested that the cell viability decreased with increasing concentration of glucose. At $30 \mathrm{mM}$ there was a significant fall; hence we chose this concentration for our experiments ahead and described it as high glucose media. We incubated the cardiomyocytes in high glucose media for $24 \mathrm{~h}$ and it was observed that there was a significant fall in viability $(p<0.05)$ (Figure $1 \mathrm{~B}$ ). In the experiment mannitol $(30 \mathrm{mM} / \mathrm{l})$ was selected as a control but failed to mimic the effect of d-glucose. The cardiomyocytes were exposed to FXN in the concentration ranging from $5,10,20$, 40 and $80 \mu \mathrm{M}$ in high glucose media $(30 \mathrm{mM} / \mathrm{l})$ for $24 \mathrm{~h}$; the results suggested that the dose of FXN at 40 and $80 \mu \mathrm{M}$ caused a significant increase in 
A

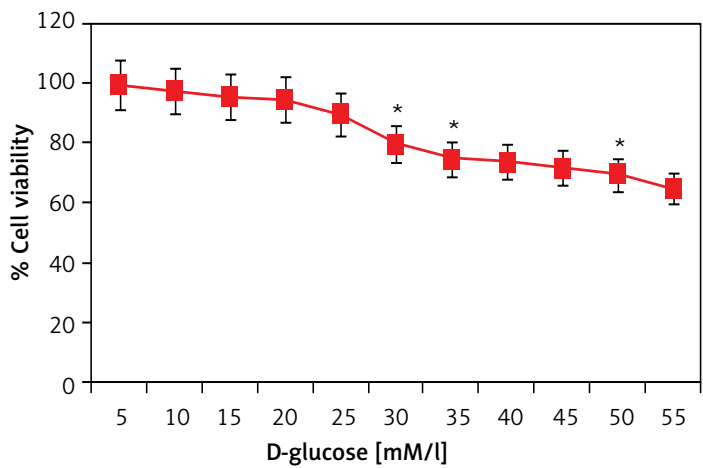

C

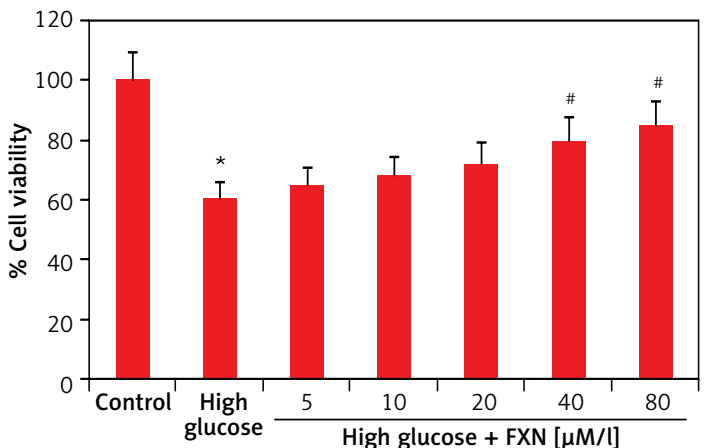

B

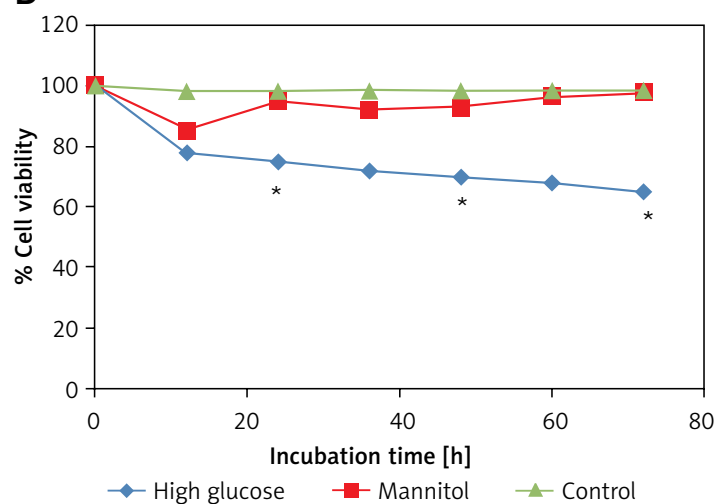

D

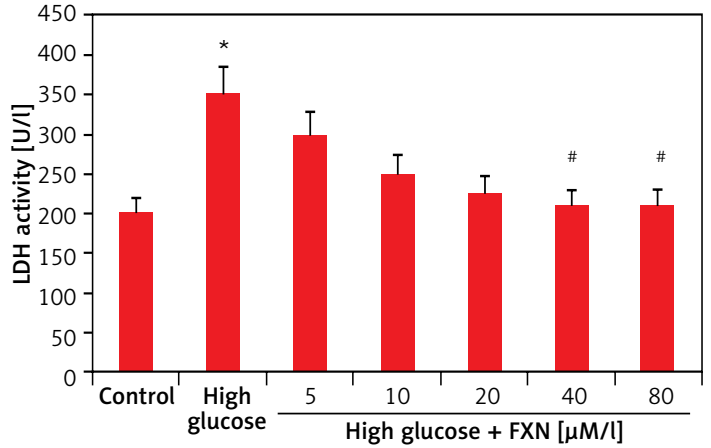

Figure 1. Fucoxanthin increases the cell viability in Iry neonatal rat cardiomyocytes treated with high glucose. A - The cell viability decreased significantly when the cells were exposed to high glucose environment (30 $\mathrm{mM} / \mathrm{l})$. B - The cell viability decreased significantly when the incubation time increased to $24 \mathrm{~h}$ in $30 \mathrm{mM} / \mathrm{lglucose}$, $30 \mathrm{mM} / \mathrm{I}$ mannitol was adopted as an osmotic control. C - Addition of fucoxanthin (40 and $80 \mu \mathrm{M} / \mathrm{l})$ increased the cell viability in high glucose treated cardiomyocytes. D - Fucoxanthin (40 and $80 \mu \mathrm{M} / \mathrm{l}$ ) decreased the release of $\mathrm{LDH}$ in the incubating medium of cardiomyocytes exposed to high glucose. ${ }^{*} P<0.05$ compared to control, ${ }^{*} p<0.05$ compared to high glucose treated rats $(n=10)$

cell viability and decreased the release of lactate dehydrogenase in the media $(p<0.05)$ (Figures $1 \mathrm{C}, \mathrm{D})$. Lactate dehydrogenase is an enzyme present in the cytosol of the animal cells; it is an oxidoreductase enzyme. The enzyme is stable and is an indicator to study the damage and toxicity of the cells and tissues. The release of LDH indicates loss of membrane integrity, suggesting cell death. The results of LDH suggested that FXN could protect the cardiac cells from injury mediated by high glucose. In the study, the cardiomyocytes were cultured in a high glucose environment and were treated with $40 \mu \mathrm{M}$ of FXN.

\section{Fucoxanthin decreased oxidative stress in iry neonatal cardiomyocytes treated with high glucose media.}

The cellular levels of reactive oxygen species in cardiomyocytes were determined by dihydroethidium. The results (Figures 2 A, B) suggested that the red fluorescence intensity increased in cardiomyocytes cultured under high glucose media versus control $(p<0.05)$. The exposure to FXN $40 \mu \mathrm{M}$ showed significant inhibition in generation of ROS $(p<0.05)$ versus the cells cultured only in high glucose media without FXN. The fluorescence by dihydroethidium was further evaluated by chromatographic assay; the results (Figure $2 \mathrm{C}$ ) suggested that the levels of ROS were elevated significantly in cells treated with high glucose, whereas a reverse pattern was seen in cell treated with FXN $(p<0.05)$.

We then evaluated the role of NADPH oxidase in the increase in production of ROS in cells cultured in high glucose media. The literature suggests that the enzyme NADPH oxidase is a complex structure made up of subunits such as $p 22^{\text {phox }}$, p67 $7^{\text {phox }}$, p47 $7^{\text {phox }}$, gp9 $1^{\text {phox }}$ and Rac1. We performed Rac1 activity assay; the results (Figures 3 A, B) demonstrated that the Rac1 activity and levels of gp91, p67 $7^{\text {hox }}$ and 447 phox were markedly upregulated due to the high glucose environment compared to control cells ( $p<0.05)$. In contrast, the FXN treatment caused a significant reversal in Rac1 activity along with expression of gp91, p67 phox and $p 47^{\text {phox }}$ compared to cells cultured only in high glucose media without FXN ( $p<$ 0.05). These results of our experiment confirmed that FXN decreased the levels of NADPH oxidase, 
A

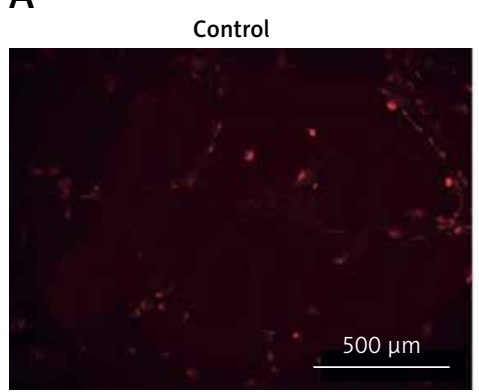

B

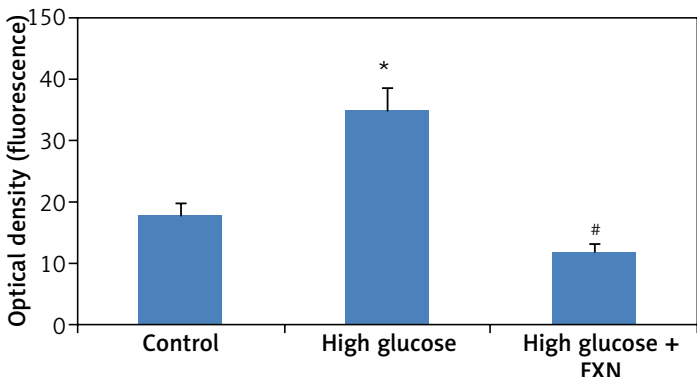

High glucose

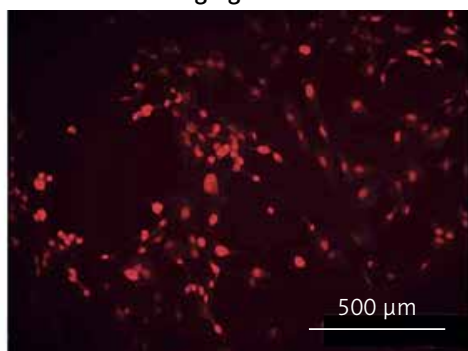

C

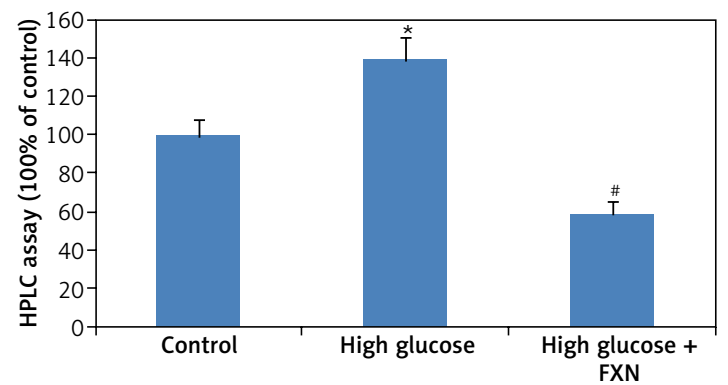

Figure 2. Fucoxanthin halted the generation of reactive oxygen species in I $^{\text {ry }}$ cardiomyocytes treated with high glucose. DHE and fluorescent probe were used for measuring intracellular levels of reactive oxygen species in cardiomyocytes. A - Cardiomyocytes staining with DHE showing representative fluorescence images (400x, scale bar: $20 \mu \mathrm{m}$ ). B - Intensity of red fluorescence (quantitative analysis). C - HPLC analysis for dihydroethidium fluorescence, fucoxanthin $40 \mu \mathrm{M}$. ${ }^{*} P<0.05$ compared to control, ${ }^{*} p<0.05$ compared to high glucose treated group $(n=10)$

A

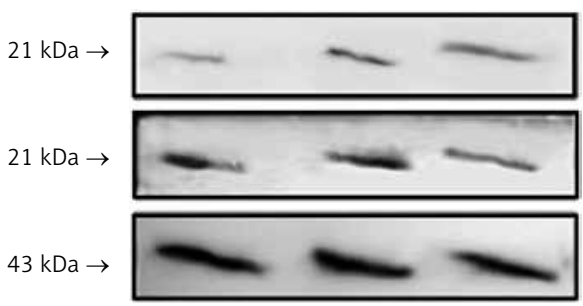

C
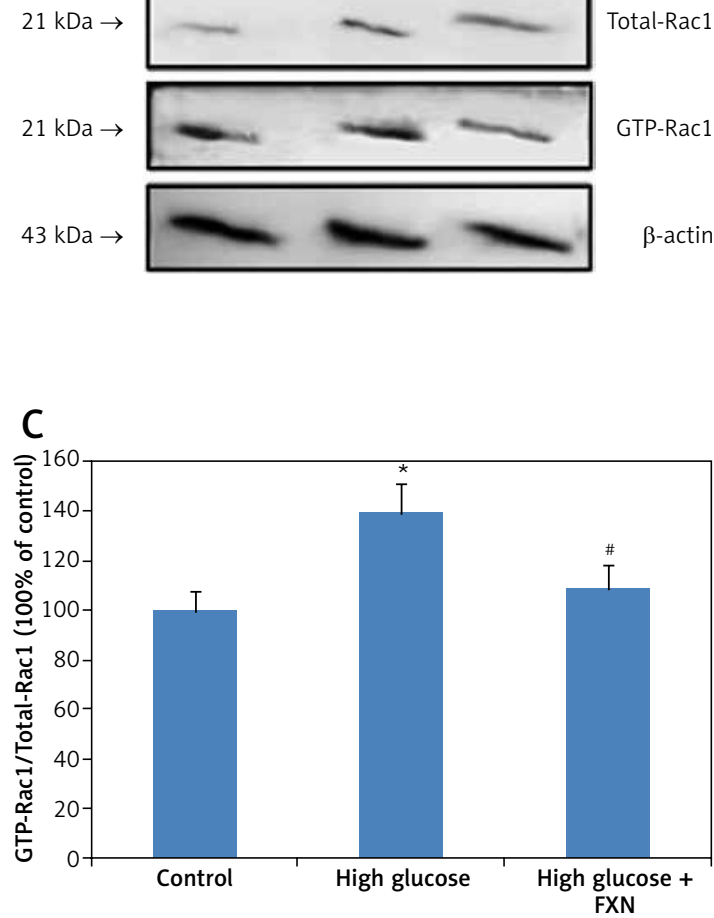

B

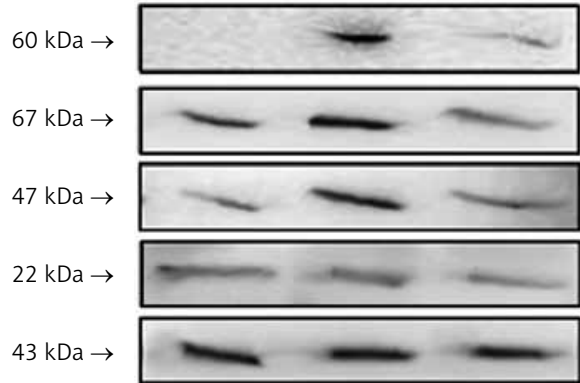

gp91 phox

p67 phox

p47 phox

p22 phox

$\beta$-actin

D

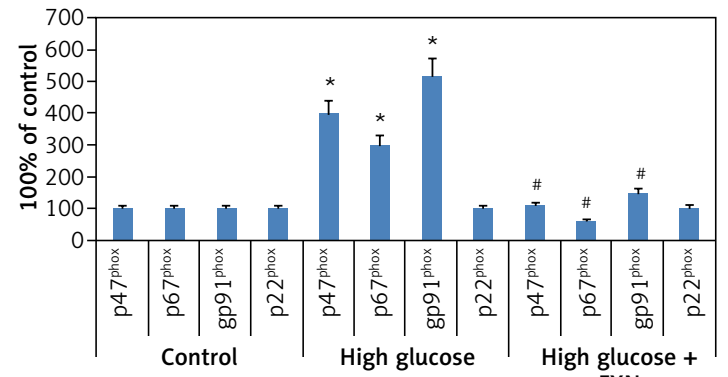

FXN

Figure 3. Fucoxanthin blocked NADPH oxidase subunits in Iry neonatal rat cardiomyocytes treated with high glucose. A - Fucoxanthin decreased the activity of Rac1 in high glucose treated cardiomyocytes. B - Fucoxanthin suppressed the levels of NADPH oxidase subunits gp91phox, p47phox, p67phox, whereas the levels of p22phox remained unaltered in cardiomyocytes treated with high glucose. Fucoxanthin $40 \mu \mathrm{M}$. C - Quantitative results showing expression of GTP-Rac1 against total Rac1. D - Quantitative results showing expression of NADPH oxidase subunits gp91 ${ }^{\text {phox }}, p 47^{\text {phox }}$ and $p 67^{\text {phox }}$ and $p 22^{\text {phox }}$. $^{*} P<0.05$ compared to control, ${ }^{\#} p<0.05$ compared to high glucose media treated group $(n=6)$ 
which further suppresses the generation of ROS in the neonatal cardiac cells receiving treatment with high glucose.

The burden of oxidative stress was further evaluated by studying the activity of endogenous antioxidant enzymes. The biochemical evaluation in cardiomyocytes (Figures 4 A-E) demonstrated that high glucose media resulted in increased formation of MDA and decreased the activity of anti-oxidant enzymes SOD, CAT, GSHpx and GSH compared to control cells $(p<0.05)$. Treatment of FXN $40 \mu \mathrm{M}$ resulted in inhibition of lipid peroxidation and improved the antioxidant status by increasing the activity of antioxidant enzymes SOD, CAT and GSHpx; the treatment also elevated the levels of GSH in cells compared to cells cultured only in high glucose media without FXN $(p<0.05)$.

\section{Fucoxanthin protects neonatal cardiomyocytes against high glucose- induced apoptosis}

The apoptosis study in cells was done by TUNEL staining as well as by flow cytometry. The results of TUNEL staining (Figures $5 \mathrm{~A}, \mathrm{~B}$ ) demonstrated an increased number of apoptosis positive cells

A

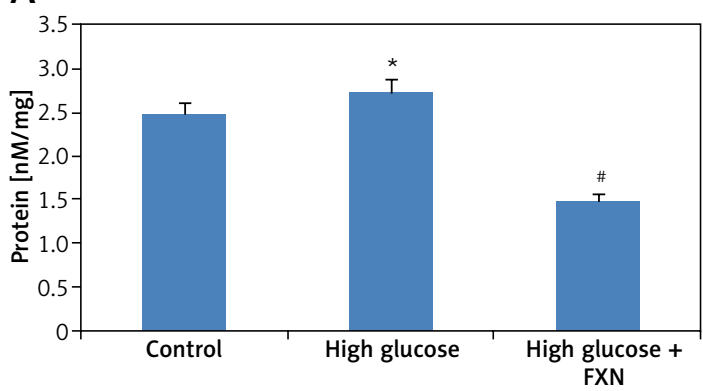

C

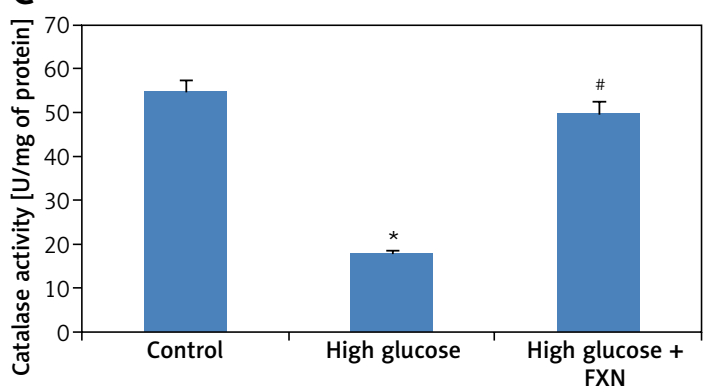

E

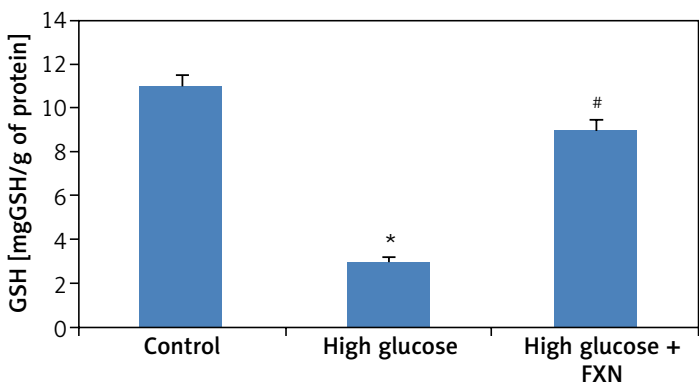

with brown staining in high glucose media treated cells compared to the control. The treatment with FXN $40 \mu \mathrm{M}$ protected the cardiac cells from glucose-induced apoptosis.

An apoptosis study by Annexin- $\mathrm{V}$ and propidium iodide $(\mathrm{PI})$ by flow cytometry was also done (Figure 5 C). The pattern Annexin V (+)/PI (-) suggested presence of a cell population exhibiting early apoptosis, whereas Annexin (+)/PI (+) indicated a cell population with delayed apoptosis. The results indicated that both cell populations, i.e. Annexin V (+)/PI (-) and Annexin (+)/PI (+), significantly increased in cells incubated in high glucose media without FXN compared to the control $(p<0.05)$. The treatment with FXN $40 \mu \mathrm{M}$ resulted in a significant decrease in both cell populations compared to cells incubated in high glucose media without FXN $(p<0.05)$.

\section{Fucoxanthin regulates the levels of $\mathrm{Bcl}-2$ and Bax in neonatal cardiomyocytes treated with high glucose}

After apoptosis studies, we evaluated the levels of Bax (pro-apoptotic protein marker) and Bcl-2 (anti-apoptotic marker) as important apop-

B

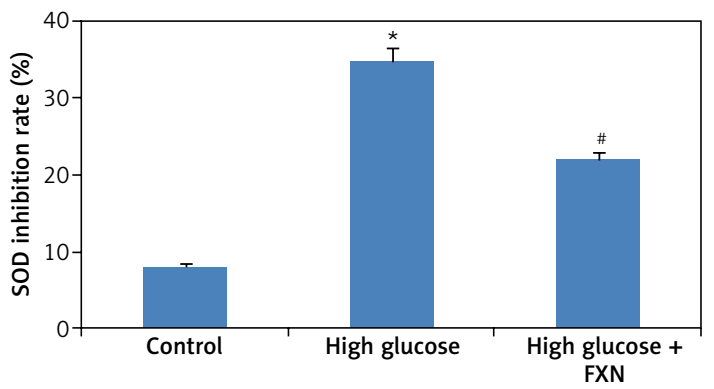

D

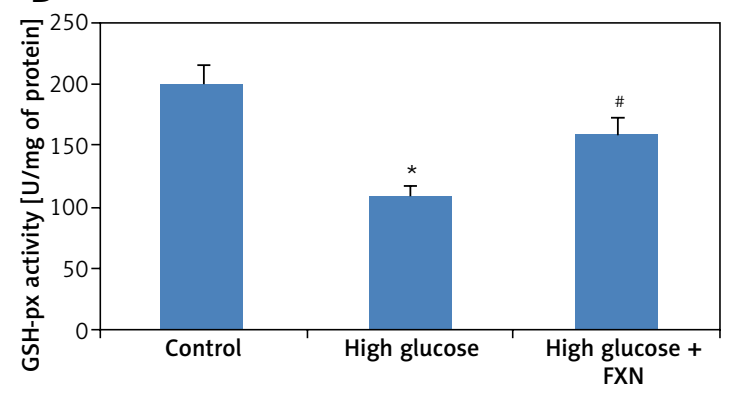

Figure 4. Fucoxanthin suppressed the levels of MDA, elevated the activity of SOD, CAT, and GSH-px, and maintained the content of GSH in I $^{\mathrm{y}}$ neonatal rat cardiomyocytes treated with high glucose media. A - Biochemical estimation of markers of oxidative stress, MDA, B - SOD, C - catalase, D - GSH-px respectively. $\mathbf{E}-$ The content of GSH was measured by biochemical analysis. Fucoxanthin: $40 \mu \mathrm{M}$. ${ }^{*} P<0.05$ compared to control, ${ }^{*} p<$ 0.05 compared to high glucose media treated group $(n=10)$ 
A

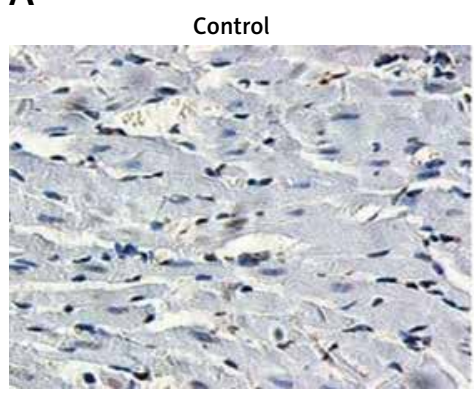

B

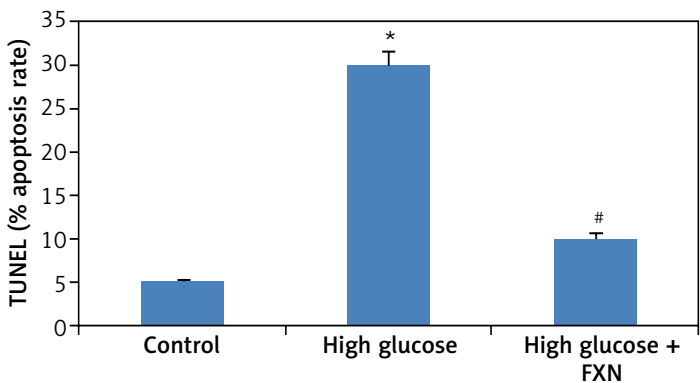

High glucose

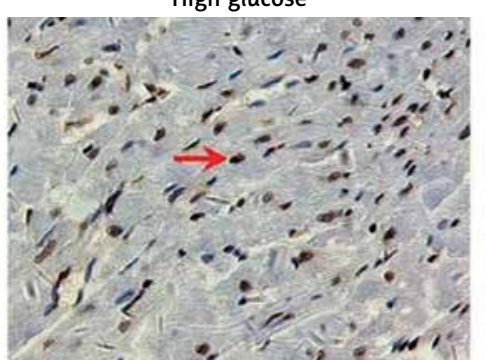

$\mathrm{C}$

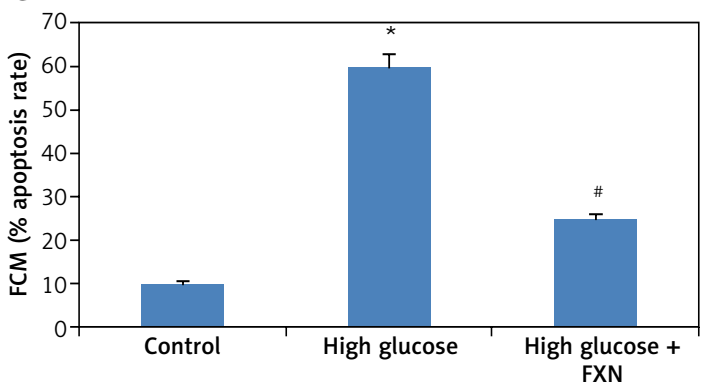

Figure 5. Fucoxanthin blocked high glucose-mediated apoptosis in Iry neonatal rat cardiomyocytes treated with high glucose. A - TUNEL staining of apoptosis induced cardiomyocytes (400x, scale bar: $20 \mu \mathrm{m})$. B - Apoptosis rate \% TUNEL staining of cardiomyocytes. C - PI and Annexin V staining for apoptotic cells by flow cytometer. Fucoxanthin $40 \mu \mathrm{M}$. ${ }^{*} P<0.05$ compared to control, ${ }^{\#} p<0.05$ compared to high glucose media treated group $(n=6)$

totic protein markers, further confirming the role of FXN against apoptosis. We extended our study to find out whether treatment with FXN suppressed apoptosis via regulating both of these important proteins. The results of immunohistochemistry (Figures 6 A, B) suggested that high glucose media caused significant up-regulation in the levels of Bax but down-regulated the levels of $\mathrm{Bcl}-2$ compared to control cardiomyocytes ( $p<0.05$ ). We further observed that FXN $40 \mu \mathrm{M}$ caused significant suppression in expression of Bax-2 and up-regulation of $\mathrm{BCl}-2$ in cardiac cells compared to cells exposed to high glucose media without FXN $(p<0.05)$. The results showing expression of both the apoptotic proteins by western blot were parallel to the immunohistochemical findings (Figure $6 \mathrm{C}$ ).

\section{Effect of fucoxanthin on AMPK and Akt/GSK-3 $\beta$ pathway in neonatal cardiomyocytes treated with high glucose}

The Akt/GSK-3 $\beta$ pathway is regarded as an important regulator for cell proliferation, survival and apoptosis. The findings of our study suggested that expression levels of both $p$-Akt and GSK$3 \beta$ were down-regulated significantly in cardiomyocytes cultured in high glucose media compared to control cells; importantly we found that treatment with FXN $40 \mu \mathrm{M}$ caused no changes in levels of $p$-Akt and GSK-3 $\beta$ in cardiomyocytes treated with high glucose (Figure 7 A). The outcomes confirmed no involvement of Akt/GSK-3 $\beta$ axis in the protective effect of FXN against high glucose induced apoptosis of cardiac cells.

Upon evaluation of AMPK, we found that treatment with FXN significantly enhanced the p-AMPK $\alpha$ in cardiomyocytes compared to those cultured in high glucose media (Figure 7 B). Treatment with DDH (10 $\mu \mathrm{M})$ (AMPK inhibitor) was found to reverse the effects of FXN-induced elevation of pAMPK $\alpha$; it decreased the levels of pAMPK $\alpha$ significantly compared to cells cultured in high glucose media with FXN $(p<0.05)$. In parallel to these findings, FXN failed to modulate the activity of Rac1, NADPH and the expression of other subunits (gp91 $1^{\text {phox }}, \mathrm{p} 47^{\text {phox }}$ and p67 ${ }^{\text {phox }}$ ) in the presence of DDH $(10 \mu \mathrm{M})$ (Figures $8 \mathrm{~A}-\mathrm{C}$ ) $(p<0.05)$. In addition, we observed that the levels of $\mathrm{Bcl}-2$ and Bax which were regulated by FXN earlier were also reversed by the DDH (Figure $9 \mathrm{~A}$ ) $(p<0.05)$. The findings hence confirmed that, when combined, FXN with DDH results in blockade in anti-apoptotic activity of FXN in glucose-induced apoptotic neonatal cardiomyocytes (Figure 9 B) $(p<0.05)$.

\section{Discussion}

As a distinctive feature of diabetes, the hyperglycemic condition is one of the important factors responsible for structural, metabolic and functional alterations in the cardiac tissues, resulting in a condition called diabetic cardiomyopathy (DC). 
A

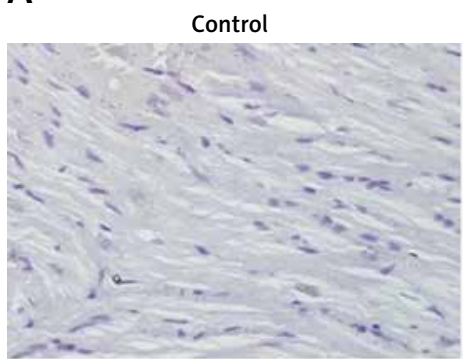

$\mathrm{Bcl}-2$

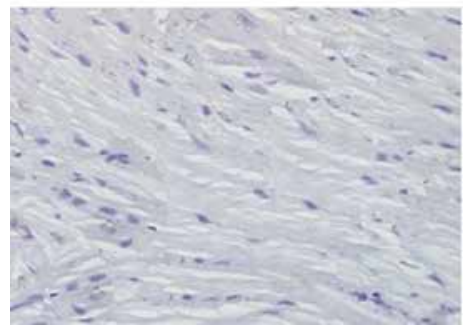

High glucose
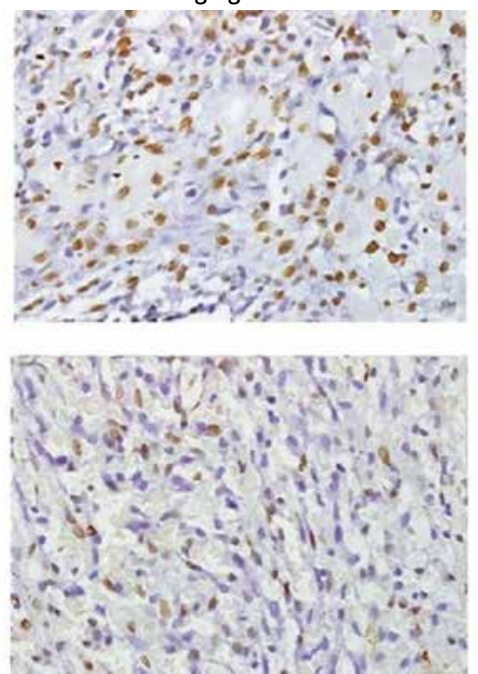
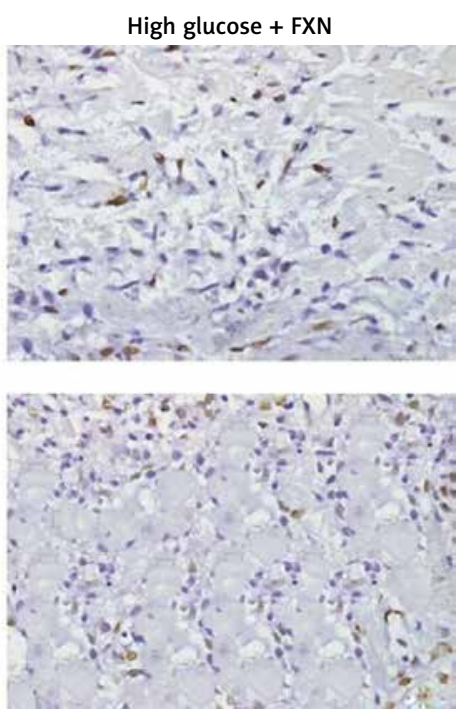

B

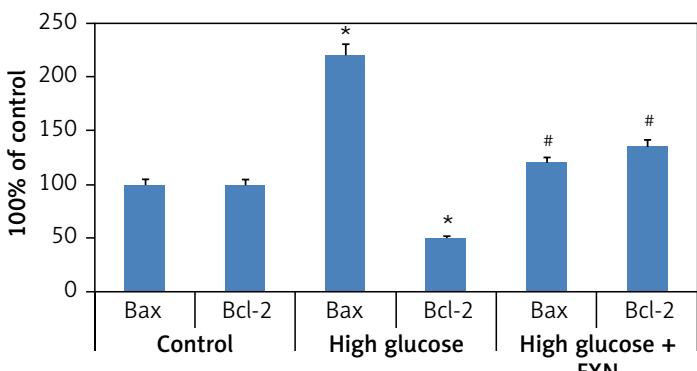

FXN

C

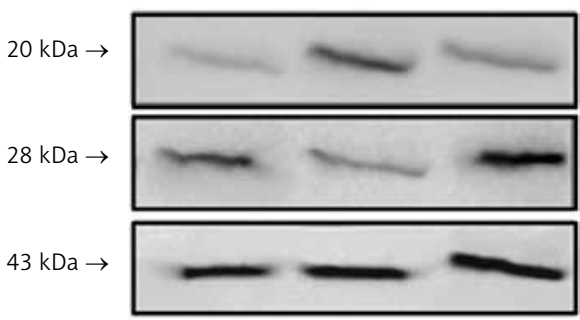

$\operatorname{Bax}$

$\mathrm{BCl}-2$

$\beta$-actin

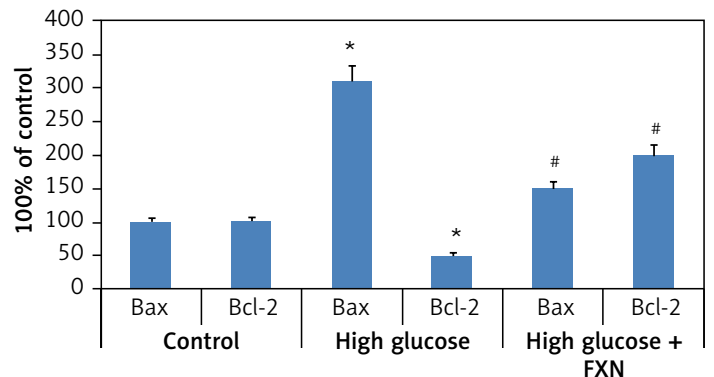

Figure 6. Fucoxanthin modulated the expression levels of $\mathrm{Bax}$ and $\mathrm{BCl}-2$ in $\mathrm{I}^{\mathrm{ry}}$ neonatal rat cardiomyocytes treated with high glucose. A - Immunohistochemical staining of $\mathrm{Bcl}-2$ and $\mathrm{Bax}$ in cardiomyocytes in control, high glucose and FXN treated cells $(400 \times$, scale bar: $20 \mu \mathrm{m})$. B - Immunostaining of Bax and Bcl-2 in control, high glucose and FXN treated cells. $\mathrm{C}$ - Western blot analysis for expression of $\mathrm{Bcl}-2$ and Bax in cardiomyocytes. Fucoxanthin $40 \mu \mathrm{M}$. ${ }^{\star} P<0.05$ compared to control, ${ }^{*} p<0.05$ compared to high glucose media treated group $(n=6)$

Abnormal glucose metabolism, which is the main feature of diabetes, can activate a series of abnormal processes in development and progression of DC [15-17]. In the present work, the neonatal cardiomyocytes when cultured in high glucose media (30 $\mathrm{mM} / \mathrm{l})$ for $24 \mathrm{~h}$ resulted in increased apoptosis and cell injury. The results were in parallel to previous findings which suggested that apoptosis of cardiomyocytes is associated with blood glucose levels [18]. Apoptosis is programmed cell death which is vital for maintaining homeostasis.
Increase in apoptosis of cardiomyocytes leads to failure of contractile cardiac tissues, which further causes cardiac remodeling, decreased contractility, hypertrophy and failure of the heart $[19,20]$. Studies have recently confirmed the importance of cardiomyocyte apoptosis in development of DC [21, 22]. A study recently correlated increased apoptosis to poor cardiovascular outcomes [23]. In the present study, treatment of FXN protected the cardiomyocytes against glucose-mediated apoptosis and cell injury. Since the process of pro- 
A
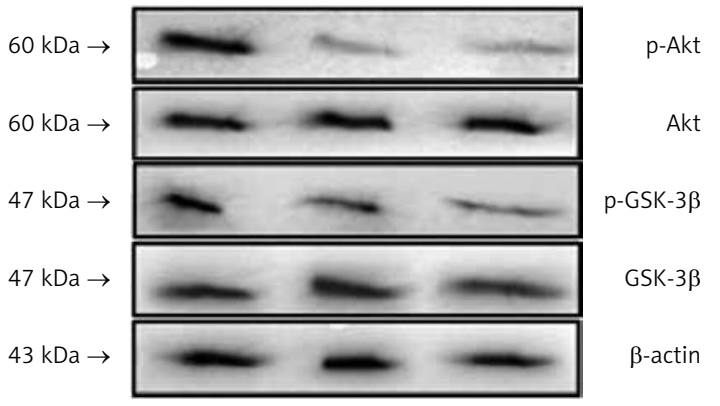

B

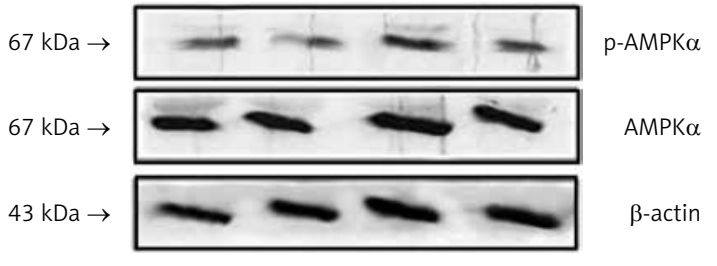

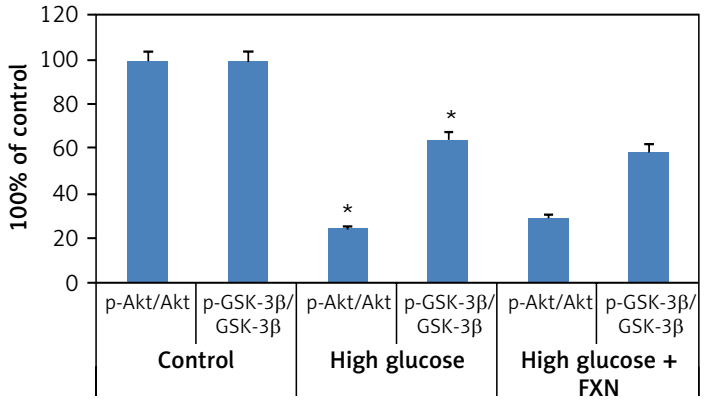

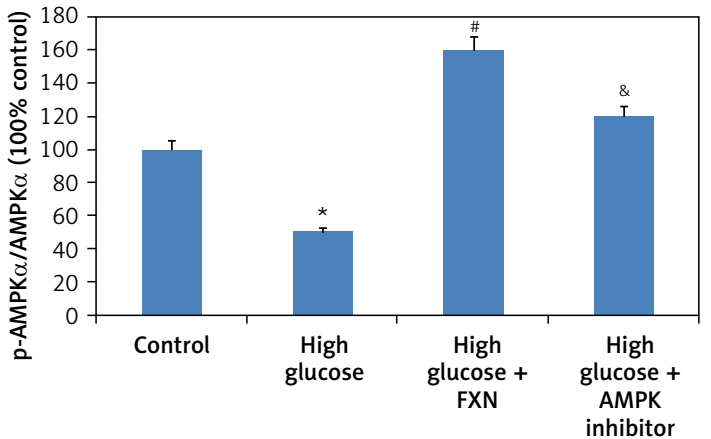

Figure 7. Effect of fucoxanthin on expression levels of AMPK and Akt/GSK-3 $\beta$ in Iry neonatal rat cardiomyocytes

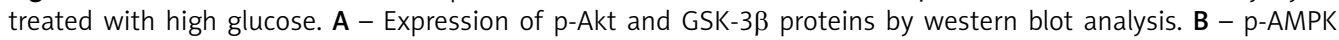
analysis by western blot study. DDH $(10 \mu \mathrm{M})$ could abolish the elevated levels of pAMPK levels by fucoxanthin in cardiac cells treated with high glucose. Fucoxanthin $40 \mu \mathrm{M}$. ${ }^{*} P<0.05$ compared to control, ${ }^{*} p<0.05$ compared to high glucose media treated group, ${ }^{8} p<0.05$ compared to high glucose + FXN treated group of cells $(n=6)$

grammed cell death, i.e. apoptosis, is modulated by number of regulatory proteins, further in our study we analyzed the expression of apoptosis regulatory proteins such as $\mathrm{Bax}$ and $\mathrm{Bcl}-2$. As predicted, the treatment with FXN reversed the Bax/ $\mathrm{Bcl}-2$ ratio in neonatal cardiac cells exposed to high glucose conditions.

Elevated oxidative stress is a major factor in development of DC. NADPH oxidase is a membrane bound enzyme and is one of the main sources of ROS in the cardiac cells. The enzyme $\mathrm{NADPH}$ oxidase is made up of multiple proteins or the subunits which are necessary for activating the enzymes in the cells. The expression of these $\mathrm{NADPH}$ oxidase subunits is altered under various pathological conditions [24]. In the present work, the exposure of cardiomyocytes to a high glucose environment resulted in up-regulation of gp91 $1^{\text {phox }}$, p6 $7^{\text {phox }}, \mathrm{p} 47^{\text {phox }}$ and Rac1 and also elevated the activity of NADPH oxidase. We also found that a high glucose environment impaired the status of the endogenous anti-oxidant system. High glucose suppressed the activity of antioxidant enzymes such as CAT, SOD, GSHpx and contents of GSH. The elevated glucose conditions enhanced lipid peroxidation. Fucoxanthin is a carotenoid having special functional groups which include 5,6-monoepoxide structure and an allen- ic bond. FXN has been reported to show antioxidant activity by curbing oxidative stress [9]. In the present work, FXN suppressed the production of ROS generated from NADPH oxidase in the neonatal cardiomyocytes cultured in an elevated glucose environment. The findings are in agreement with previous studies which suggest that FXN blocks NADPH-mediated reactive oxygen species in 3T3-L1 adipocytes [25] and neuronal cells [26]. FXN has been found to elevate the activity of antioxidant enzymes such as SOD, CAT and GSHpx, and also it improves content of GSH at the cellular level [27]. In our present work, FXN attenuated oxidative stress mediated by a high glucose environment by modulating ROS, as evidenced by elevation of activity of SOD, CAT and GSHpx. The treatment improved levels of GSH and suppressed MDA.

In the present work we studied generation of ROS mediated by NADPH oxidase only, and the role of FXN in other sources producing reactive oxygen species such as mitochondria in cardiomyocytes still remains to be unexplored. Here we identified the pathway responsible for the beneficial effect of FXN in cardiac cells exposed to high glucose. AMPK is vital to maintain cellular stores of energy by shifting it to pathways which produce ATP. Activation of AMPK has been found to 
A

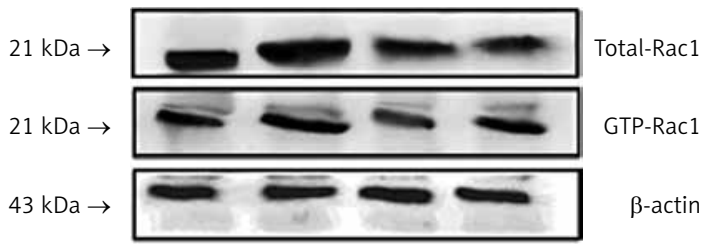

B

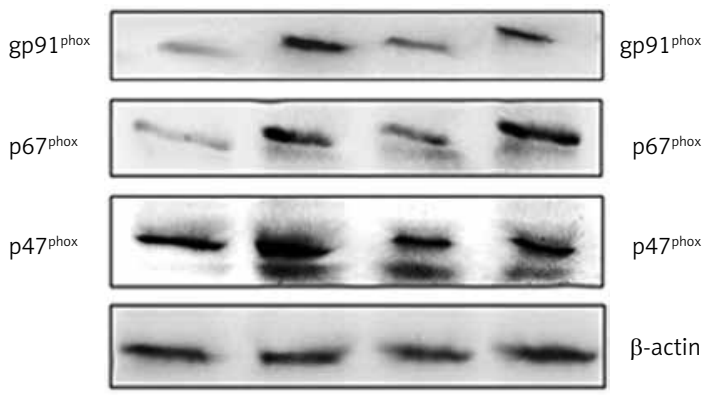

C

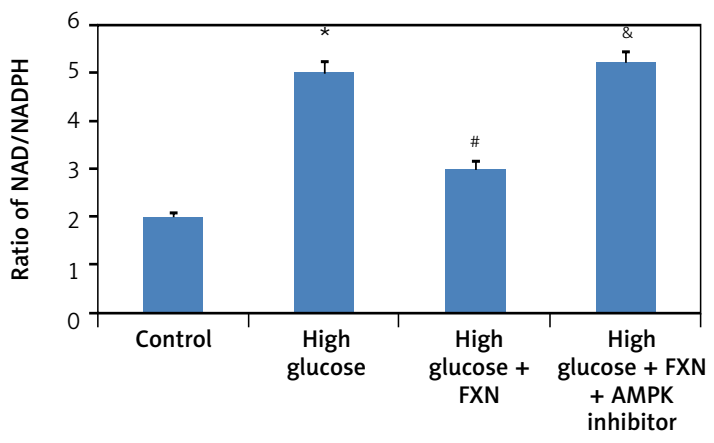

protect against a number of cardiac disorders associated with apoptosis via insulin dependent and independent pathways $[28,29]$. In our study, we demonstrated that activation of AMPK is involved in the protective action of FXN on neonatal cardiomyocytes via suppressing the oxidative stress mediated by a high glucose environment. Our findings were in agreement with an earlier study which suggested that FXN exerts a protective effect against high glucose induced oxidative stress in human umbilical cells and in a zebrafish model [30]. In a study, it was confirmed that activation of NADPH oxidase due to the hyperglycemic condition in cardiac cells is independent of glucose metabolism [31, 32]. Our findings provided novel evidence that FXN exerts a protective effect on cardiomyocytes in DC.

In conclusion, our study established that FXN when exposed to $\mathrm{I}^{\mathrm{y}}$ neonatal cardiomyocytes subjected to a high glucose environment exert-
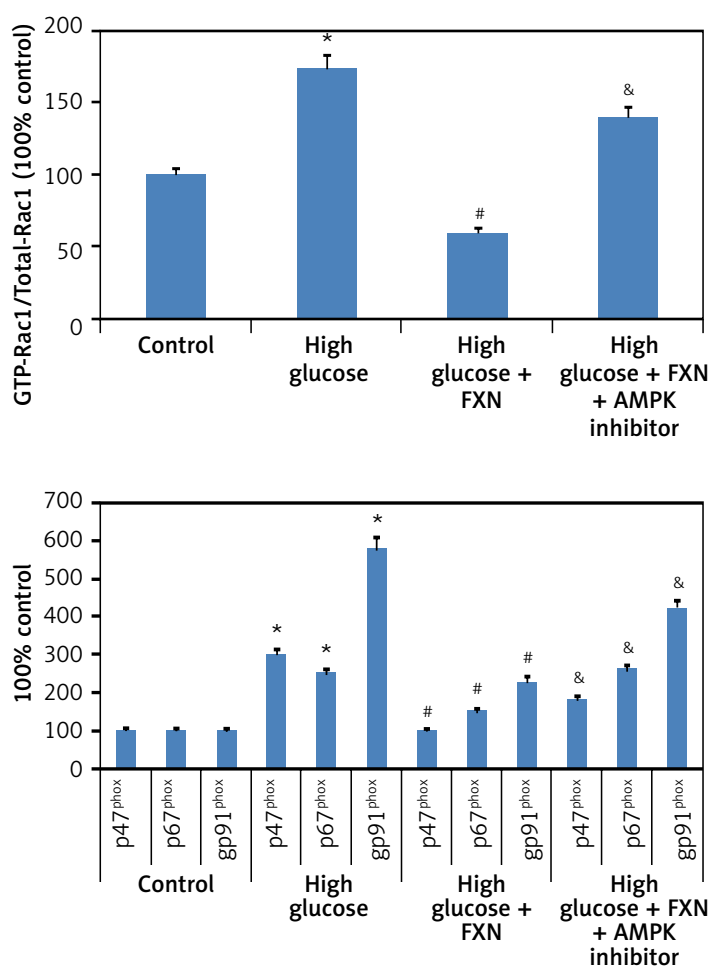

Figure 8. Blockade of AMPK abolished the effect of fucoxanthin on the activity of NADPH oxidase and expression its subunit in Iry neonatal rat cardiomyocytes treated with high glucose. A - Fucoxanthin suppressed the activity of Rac1, which was blocked by $\mathrm{DDH}$. B - Fucoxanthin along with $\mathrm{DDH}$ reversed the expression levels of NADPH oxidase subunits p67 $7^{\text {phox }}, \mathrm{p} 47^{\text {phox }}$, and gp91 ${ }^{\text {phox }} . \mathrm{C}-\mathrm{DDH}$ reversed the inhibition of NADPH activity mediated by fucoxanthin. Fucoxanthin $40 \mu \mathrm{M}$. ${ }^{\star} P<0.05$ compared to control, $p<0.05$ compared to high glucose media treated group, ${ }^{\&} p<0.05$ compared to high glucose + FXN treated group of cells $(n=6)$

ed a protective effect by halting apoptosis via blocking NADPH-induced ROS production and improving the activities of antioxidant enzymes of cardiomyocytes. We also confirmed that these effects of FXN involve the AMPK cascade. Altogether our findings confirm the therapeutic potential of FXN in treating diabetes-associated cardiac diseases.

\section{Acknowledgments}

This study was supported by Medical Research Projects of Wuhan Municipal Health Planning Commission (No. WX18Z22).

We express thanks to our funding agency, Medical Research Projects of Wuhan Municipal Health Planning Commission. We are also grateful to the staff and management of Wuhan Children's Hospital China for creating necessary facilities for the work. 
A

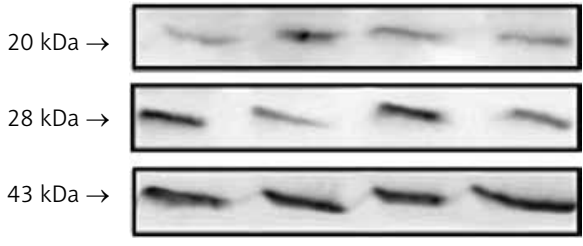

Bax

$\mathrm{Bcl}-2$

$\beta$-actin

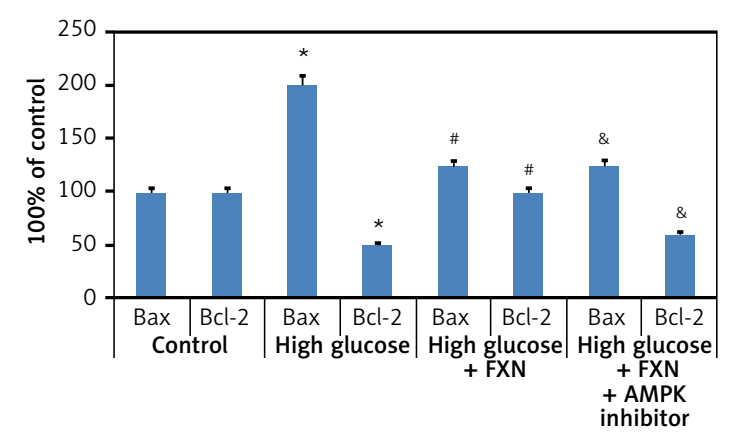

High glucose + FXN

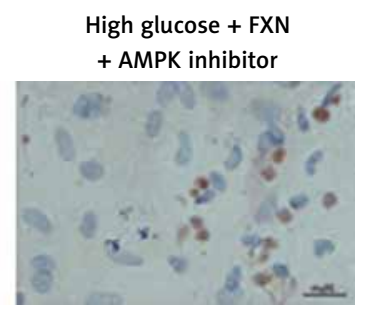

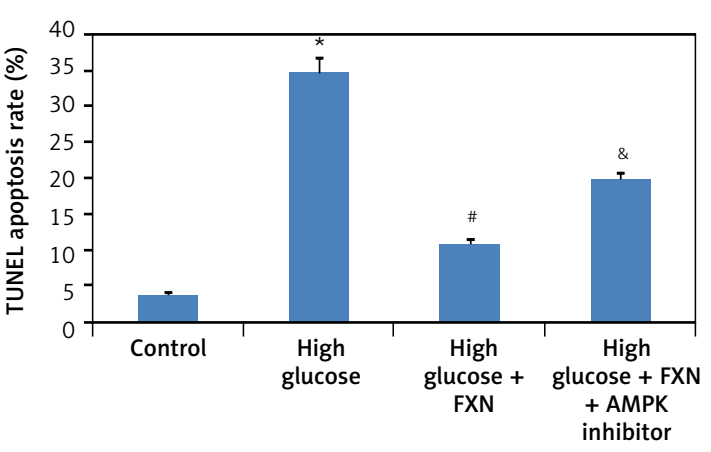

\section{Conflict of interest}

The authors declare no conflict of interest.

\section{References}

1. Forbes JM, Cooper ME. Mechanisms of diabetic complications. Physiol Rev 2013; 93: 137-88.

2. Schilling JD, Mann DL. Diabetic cardiomyopathy: bench to bedside. Heart Fail Clin 2012; 8: 619-31.

3. Ansley DM, Wang B. Oxidative stress and myocardial injury in the diabetic heart. J Pathol 2013; 229: 232-41.

4. Bonnefont-Rousselot D, Bastard JP, Jaudon MC, Delattre J. Consequences of the diabetic status on the oxidant/ antioxidant balance. Diabetes Metab 2000; 26: 163-76.

5. Wold LE, Ceylan-Isik AF, Ren J. Oxidative stress and stress signaling: menace of diabetic cardiomyopathy. Acta Pharmacol Sin 2005; 26: 908-17.

6. Kuroda J, Sadoshima J. NADPH oxidase and cardiac failure. J Cardiovasc Transl Res 2010; 3: 314-20.

7. Gao L, Mann GE. Vascular NAD(P)H oxidase activation in diabetes: a double-edged sword in redox signalling. Cardiovasc Res 2009; 82: 9-20.

8. Sugawara T, Baskaran V, Tsuzuki W, Nagao A. Brown algae fucoxanthin is hydrolyzed to fucoxanthinol during absorption by Caco-2 human intestinal cells and mice. J Nutr 2002; 132: 946-51.

9. Yan X, Chuda Y, Suzuki M, Nagata T. Fucoxanthin as the major antioxidant in Hijikia fusiformis, a common
Figure 9. Inhibition of AMPK aggravated apoptosis in Iry neonatal rat cardiomyocytes treated with high glucose. A - DDH blocked the effect of fucoxanthin on expression of Bcl-2 and Bax. B - Image showing apoptosis in myocytes by TUNEL staining. Quantitative analysis of cardiomyocytes subjected to TUNEL staining. Fucoxanthin $40 \mu \mathrm{M} .{ }^{*} P<0.05$ compared to control, $\#<0.05$ compared to high glucose media treated group, ${ }^{\&} p<0.05$ compared to high glucose + FXN treated group of cells $(n=6)$

edible seaweed. Biosci Biotechnol Biochem 1999; 63: 605-7.

10. Liu Y, Zheng J, Zhang Y, et al. Fucoxanthin activates apoptosis via inhibition of PI3K/Akt/mTOR pathway and suppresses invasion and migration by restriction of $\mathrm{p} 38-\mathrm{MMP}-2 / 9$ pathway in human glioblastoma cells. Neurochem Res 2016; 41: 2728-51.

11. Maeda H. Nutraceutical effects of fucoxanthin for obesity and diabetes therapy: a review. J Oleo Sci 2015; 64: 125-32.

12. Kovacic S, Soltys CL, Barr AJ, Shiojima I, Walsh K, Dyck JR. Akt activity negatively regulates phosphorylation of AMP-activated protein kinase in the heart. J Biol Chem 2003; 278: 39422-7.

13. Tominaga $H$, Shiga $M$, Sasamoto $K$, Ohkura $Y$, Ueno K. A combined assay of cell viability and in vitro cytotoxicity with a highly water-soluble tetrazolium salt, neutral red and crystal violet. Biol Pharm Bull 1996; 19: 1518-20.

14. Zielonka J, Hardy M, Kalyanaraman B. HPLC study of oxidation products of hydroethidine in chemical and biological systems: ramifications in superoxide measurements. Free Radic Biol Med 2009; 46: 329-38.

15. Robertson RP, Harmon J, Tran PO, Poitout V. Beta-cell glucose toxicity, lipotoxicity, and chronic oxidative stress in type 2 diabetes. Diabetes 2004; 53 (Suppl. 1): S119-24.

16. Yao D, Brownlee M. Hyperglycemia-induced reactive oxygen species increase expression of the receptor for advanced glycation end products (RAGE) and RAGE ligands. Diabetes 2010; 59: 249-55. 
17. Fang ZY, Prins JB, Marwick TH. Diabetic cardiomyopathy: evidence, mechanisms, and therapeutic implications. Endocr Rev 2004; 25: 543-67.

18. Fiordaliso F, Li B, Latini R, et al. Myocyte death in streptozotocin-induced diabetes in rats in angiotensin II- dependent. Lab Invest 2000; 80: 513-27.

19. Dhalla NS, Takeda N, Rodriguez-Leyva D, Elimban V. Mechanisms of subcellular remodeling in heart failure due to diabetes. Heart Fail Rev 2014; 19: 87-99.

20. Foo RS, Mani K, Kitsis RN. Death begets failure in the heart. J Clin Invest 2005; 115: 565-71.

21. Cai L, Li W, Wang G, Guo L, Jiang Y, Kang YJ. Hyperglycemia-induced apoptosis in mouse myocardium: mitochondrial cytochrome C-mediated caspase- 3 activation pathway. Diabetes 2002; 51: 1938-48.

22. Kuethe F, Sigusch HH, Bornstein SR, Hilbig K, Kamvissi V, Figulla HR. Apoptosis in patients with dilated cardiomyopathy and diabetes: a feature of diabetic cardiomyopathy? Horm Metab Res 2007; 39: 672-6.

23. Bernecker OY, Huq F, Heist EK, Podesser BK, Hajjar RJ. Apoptosis in heart failure and the senescent heart. Cardiovasc Toxicol 2003; 3: 183-90.

24. Ritchie RH, Quinn JM, Cao AH, et al. The antioxidant tempol inhibits cardiac hypertrophy in the insulin-resistant GLUT4-deficient mouse in vivo. J Mol Cell Cardiol 2007; 42: 1119-28.

25. Seo MJ, Seo YJ, Pan CH, Lee OH, Kim KJ, Lee BY. Fucoxanthin suppresses lipid accumulation and ROS production during differentiation in 3T3-L1 adipocytes. Phytother Res 2016; 30: 1802-8.

26. Zhang L, Wang H, Fan Y, et al. Fucoxanthin provides neuroprotection in models of traumatic brain injury via the Nrf2-ARE and Nrf2-autophagy pathways. Sci Rep 2017; 7: 46763.

27. Ha AW, Na SJ, Kim WK. Antioxidant effects of fucoxanthin rich powder in rats fed with high fat diet. Nutr Res Pract 2013; 7: 475-80.

28. Chen K, Li G, Geng F, et al. Berberine reduces ischemia/ reperfusion-induced myocardial apoptosis via activating AMPK and PI3K-Akt signaling in diabetic rats. Apoptosis 2014; 19: 946-57.

29. Sasaki H, Asanuma H, Fujita M, et al. Metformin prevents progression of heart failure in dogs: role of AMP-activated protein kinase. Circulation 2009; 119: 2568-77.

30. Kang M, Lee $S$, Lee W, et al. Protective effect of fucoxanthin isolated from Ishige okamurae against high-glucose induced oxidative stress in human umbilical vein endothelial cells and zebrafish model. J Funct Foods 2014; 11: 304-12.

31. Balteau M, Tajeddine N, de Meester C, et al. NADPH oxidase activation by hyperglycaemia in cardiomyocytes is independent of glucose metabolism but requires SGLT1. Cardiovasc Res 2011; 92: 237-46.

32. Kaczmarczyk-Sedlak I, Folwarczna J, Sedlak L, et al. Effect of caffeine on biomarkers of oxidative stress in lenses of rats with streptozotocin-induced diabetes. Arch Med Sci 2019; 15: 1073-80. 